\title{
Rancang Bangun Penyeimbang Arus Beban Pada Sistem 3 Fasa Menggunakan Mikrokontroller Atmega 2560
}

\author{
A.M.Putra ${ }^{1}$,C.G.I. Partha ${ }^{2}$, I.N. Budiastra ${ }^{3}$
}

\begin{abstract}
The design of balancing the load current on threephase systems using a microcontroller ATMega 2560 is a tool that serves to reduce the power loss due to the load current unbalance the current flows in the neutral phase on three-phase systems.The methods in making this tool is divided into two parts: first, the design of hardware consist of designing electronic components which are used by the current sensor circuits, relay, LCD (Liquid Crystal Display) etc. Second, the design of software is a tool listing program procedure including the monitoring program displays the current of each phase on LCD using the Arduino IDE. SCT013-030 current sensor used, the output of the current sensor is connected to the pin ADC (Analog to Digital Converter) microcontroller ATMega 2560.The result of the test design of balancing load current on three-phase system using a microcontroller ATMega 2560 succeed balancing the load current by moving the channel load of sequence number load the smallest connected to the phase with the current biggest load toward a phase that has a load current smallest when neutral current exceeds the limit is permitted.
\end{abstract}

Intisari-Rancang bangun penyeimbangan arus beban pada sistem 3 fasa menggunakan mikrokontroler ATMega 2560 merupakan suatu alat yang berfungsi untuk mengurangi rugi daya akibat ketidakseimbangan arus beban adanya arus mengalir ke fasa netral pada sistem 3 fasa.Metode dalam pembuatan alat ini dibagi menjadi dua bagian yaitu pertama perancangan perangkat keras (hardware) terdiri dari perancangan komponen elektronika yang digunakan dengan rangkaian sensor arus, relay, LCD (Liquid Crystal Display) dan yang lainya. Kedua, perancangan perangkat lunak (software) berupa program kerja alat termasuk program monitoring menampilkan arus tiap fasa pada LCD menggunakan Arduino IDE. Sensor arus menggunakan SCT013-030, output dari sensor arus dihubungkan dengan pin ADC (Analog to Digital Converter) mikrokontroler ATMega 2560.Hasil dari pengujian rancang bangun penyeimbang arus beban pada sistem 3 fasa menggunakan mikrokontroler ATMega 2560 berhasil karena alat melakukan penyeimbangan arus beban dengan memindahkan saluran beban dari urutan nomor beban terkecil yang tersambung ke fasa dengan arus beban terbesar menuju fasa yang memiliki arus beban terkecil ketika arus netral melebihi batas yang diijinkan.

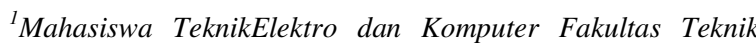
Universitas Udayana, Kampus Bukit Jimbaran, Badung Bali. 80361, Tel.0361703315 fax.0361703315; email :gus_mardi93@yahoo.com

${ }^{2,3}$ Dosen Teknik Elektro dan Komputer Fakultas Teknik Universitas Udayana, Kampus Bukit Jimbaran, Badung Bali. 80361, Tel.0361703315 fax.0361703315; email :cokindra@unud.ac.id
Kata kunci : Penyeimbangan arus beban, sistem monitoring, SCT013-030, mikrokontroler ATMega 2560, saluran beban, arus netral.

\section{PENDAHULUAN}

PT. PLN (Persero) adalah perusahaan sekaligus merupakan perusahaan milik negara penyedia listrik umum untuk seluruh masyarakat di Indonesia. Listrik menjadi kebutuhan utama dalam menjalankan aktivitas yang memanfaatkan perkembangan teknologi. Listrik dihasilkan melalui konversi energi thermal dan non-thermal atau fosil dan non-fosil. Listrik yang dihasilkan kemudian dialirkan menuju rumah-rumah pelanggan masyarakat umum, industri dan komersial.

Salah satu permasalahan dari pihak PT. PLN (Persero) adalah losses saat mendistribusikan listrik menuju pelanggan karena ketidakseimbangan arus beban pada trafo distribusi. Arus beban tidak seimbang mengakibatkan adanya arus yang mengalir ke fasa netral sehingga harus dilakukan penyeimbangan arus beban. Berdasarkan data PT. PLN (Persero) Rayon Kuta, permasalahan ketidakseimbangan arus beban di trafo distribusi pada bulan Juli 2015 tercatat 27 permasalahandengan komposisi 15 permasalahan berhasil diselesaikan, 4 permasalahan batal dikerjakan karena arus netral turun dibawah nilai batas dan 8 permasalahan belum dapat diselesaikan. Sehingga terdapat 19 permasalahan terselesaikan dengan rata-rata arus pada fasa netral panel hubung bagi sebesar 81,47 ampere.

PT. PLN (Persero) memiliki bagian Pelayanan Teknik yang bertugas mengatasi masalah ketidakseimbangan arus beban di trafo distribusi. Salah satu tujuan dibentuknya bagian Pelayanan Teknik untuk mengurangi losses akibat arus beban tidak seimbang. Kenyataan dilapangan petugas membutuhkan banyak waktu saat menuju lokasi trafo, mengukur arus fasa utama dan arus tiap saluran kemudian memadamkan sistem sesaat untuk melakukan pemindahan saluran beban hanya terhadap jenis beban satu fasa dan beban non-essential. Semakin lama arus mengalir pada fasa netral, semakin banyak rugi-rugi daya yang dialami.

Berdasarkan fakta tersebut diperlukan solusi untuk mengurangi losses karena arus beban yang tidak seimbang. Solusinya adalah memasang sensor arus yang terintegrasi dengan relay penghubung antara jalur beban pelanggan dan saluran fasa pada panel hubung bagi yang dikontrol dengan mikrokontroler. Dalam penelitian ini akan dibuat prototype 
rancang bangun penyeimbangan arus beban pada sistem 3 fasa menggunakan mikrokontroler ATMEGA 2560.

Alat ini akan bekerja dengan program yang sudah dibuat berdasarkan prosedur operasional bagian Pelayanan Teknik. Jika arus pada fasa netral melebihi batas maka relay detectorakan memberikan informasi beban yang tersambung pada fasa dengan arus beban terbesar dan memindahkannya menuju fasa dengan arus beban terkecil. Pemindahan jalur beban menuju salah satu fasa dengan arus beban terkecil dilakukan dengan menggunakan relay. Sebagai interface pada LCD ditampilkan nilai arus fasa utama termasuk fasa netral dan keterangan sedang dilakukan penyeimbangan beban. Setelah penyeimbangan beban sensor arus kembali mendeteksi nilai arus pada fasa netral untuk menentukan jika perlu dilakukan penyeimbangan arus beban kembali.

\section{TINJAUAN PUSTAKA}

\section{A. Saluran Jaringa Tegangan Rendah}

Jaringan Tegangan Rendah (JTR) adalah saluran yang menghubungkan antara Saluran Udara Tegangan Menengah (SUTM) dengan Saluran tenaga Listrik Tegangan Rendah (SLTR) atau Tegangan Rumah (TR). Pada JTR terdapat gardu distribusi yang terdiri dari berbagai komponen untuk mendistribusikan tenaga listrik tergantung dari jenis konstruksinya. Komponen secara umum terdiri dari fuse cutout, trafo step-down, lightning arrester, fuse utama, busbar/rel fasa, fuse saluran busbar/rel grounding.

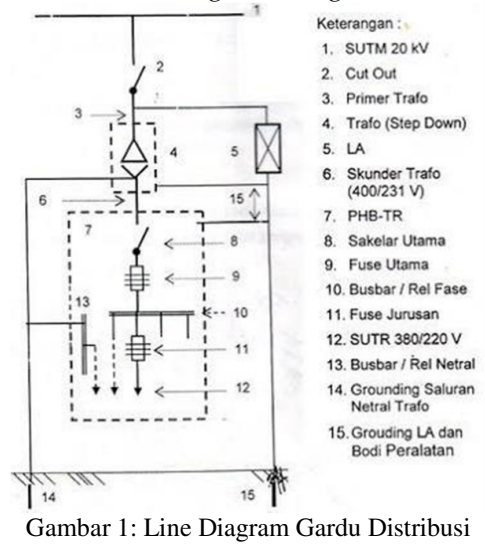

Pada gambar 1 dapat dilihat dari saluran udara tegangan menengah $20 \mathrm{kV}$ sebelum menuju trafo distribusi yang menggunakan trafo step-down terdapat fuse cut-out yang berfungsi sebagai pengaman trafo. Selain itu juga terdapat lightning arrester yang berfungsi untuk mengamankan trafo dan peralatan gardu distribusi lainnya bila terjadi tegangan lebih termasuk surja petir. Pada sisi sekunder dari trafo distribusi terdapat saklar utama dan fuse utama sebagai pengaman. Selanjutnya terdapat busbar atau rel fasa utama yang akan dibagi menjadi beberapa saluran sesuai dengan jumlah beban yang dibebankan pada trafo. Fuse saluran dipasang untuk mengamankan jalur setiap saluran apabila terdapat arus berlebih. Peralatan pengaman lainnya seperti grounding trafo dan grounding lightning arrester[1].

\section{B. Penyeimbangan Arus Beban pada Sistem 3 Fasa}

Arus beban yang tidak seimbang disebabkan oleh mendominasinya pelanggan dengan beban satu fasa dibandingkan pelanggan yang menggunakan beban tiga fasa. Sehingga pelanggan dengan beban satu fasa disambungkan ke salah satu fasa yang terdapat dalam sistem tiga fasa. Penggunaan energi listrik pelanggan satu fasa seringkali memiliki jam operasi yang berbeda, akibatnya arus beban yang mengalir di setiap fasa tidak akan sama. Situasi ini menyebabkan adanya arus yang cukup besar mengalir pada fasa netral. Efek lain yang ditimbulkan adalah sudut fasa yang dibentuk tidak lagi $120^{\circ}$ dan membuat arus beban trafo menjadi tidak seimbang. Definisi keadaan seimbang adalah suatu keadaan dimana :

1. Ketiga vektor arus atau tegangan sama besar.

2. Ketiga vektor arus/tegangan membentuk sudut $120^{\circ}$ satu sama lain.

3. Besarnya nilai arus netral adalah 0 ampere.

Sedangkan yang dimaksud dengan keadaan tidak seimbang apabila salah satu dari dua syarat tidak terpenuhi atau kedua syarat tidak terpenuhi sama sekali, sehingga terdapat tiga kemungkinan yang menyebabkan situasi beban tidak seimbang seperti:

1. Ketiga vektor sama besar dan tidak membentuk sudut $120^{\circ}$ satu sama lain.

2. Ketiga vektor tidak sama besar dan membentuk sudut $120^{\circ}$ satu sama lain.

3. Ketiga vektor tidak sama besar dan tidak membentuk sudut $120^{\circ}$ satu sama lain.

4. Terdapat nilai arus yang mengalir pada kawat netral.

Akibat dari arus beban tidak seimbang hanya mempengaruhi sisi sekunder dari trafo distribusi (fasa-R, fasa$\mathrm{S}$, fasa-T dan fasa-N) dan mengalirnya arus pada fasa netral yang merupakan losses atau rugi daya bagi pihak penyedia listrik. Situasi ini dapat diatasi dengan melakukan switching beban. Penyeimbangan arus beban dilakukan dalam beberapa tahap yaitu pengukuran awal, pemetaan dan pemindahan saluran pelanggan dan pengukuran akhir. Pengukuran awal dimaksudkan untuk mengetahui kondisi arus yang mengalir pada setiap fasa dan ketidakseimbangan arus beban yang terjadi. Selanjutnya dilakukan pemindahan beban dengan memindahkan saluran pelanggan yang terhubung ke fasa yang memiliki arus beban terbesar menuju fasa dengan arus terkecil. Tahap terakhir dengan mengukur arus pada setiap fasa untuk mengetahui apakah arus beban sudah seimbang [2].

\section{Mikrokontroler Arduino}

Arduino adalah mikrokontroler singleboard yang dirancang untuk memudahkan penggunanya karena sifatnya yang open-source. Mikrokontroler jenis Atmel AVR adalah mikrokontroler yang digunakan pada arduino. Mikrokontroler AVR menggunakan basis arsitektur AVR RISC (Reduced Intrution Set Computer) mengacu pada arsitektur Harvard, yang dibuat oleh Atmel tahun 1996. Adapun kelebihan yang dimiliki adalah [3]:

1. Lintas platform yaitusoftware arduino dapat dijalankan pada sistem operasi windows, macintosh OSX dan 
linux, sementara platform lain umumnya terbatas hanya pada Windows.

2. Sangat mudah dipelajari dan digunakan karena bahasa pemrogramannya masih sama seperti bahasa $\mathrm{C}$.

3. Open source, baik dari sisi hardware maupun softwarenya.

4. Memiliki modul siap pakai (shield) yang bisa ditancapkan pada board arduino yaitu shield GSM/GPRS, GPS, Ethernet, SD Card dan lain-lain.

Arduino Mega 2560 R3 pada dasarnya adalah mikrokontroler yang menggunakan ATMega 2560 sebagai pengolah data. Modul ini memiliki 54 pin input dan output diantaranya 15 pin dapat digunakan sebagai output PWM, 16 pin input analog, 4 UARTs untuk port serial hardware, crystal oscillator $16 \mathrm{MHz}$, koneksi USB, input power, ICSP header dan tombol reset. Hal ini sudah termasuk semua yang dibutuhkan untuk mengaktifkan sebuah mikrokontroler seperti menghubungkan ke komputer dengan kabel USB atau dengan sumber yang berasal dari adaptor AC ke DC atau baterai. Arduino Mega 2560 R3 dapat digabungkan dengan perangkat atau modul yang di pasangkan pada Arduino Uno, Duemilanover atau Diecimila [3].

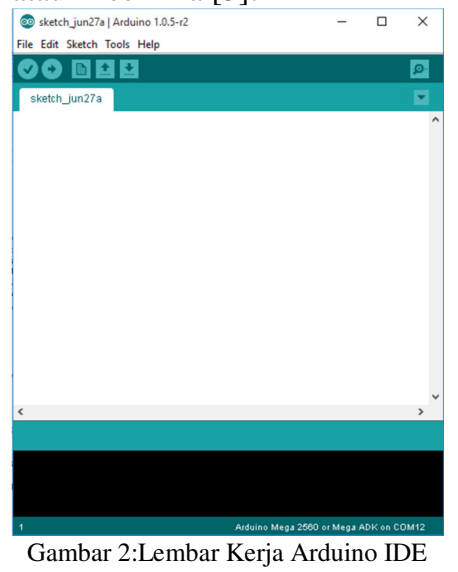

Tampilan softwareArduino IDE (Intergrated Development Environment) terlihat pada gambar 2 yang digunakan untuk membuat kode program dilengkapi dengan fitur pada toolbar memiliki fungsi yang dapat membantu dalam menghubungkan program dengan mikrokontroler arduino. Program yang dibuat dengan arduino IDE disebut dengan sketches. File sketches yang dibuat selanjutnya akan disimpan dengan menggunakan format ino. Berbagai fitur yang dapat digunakan dalam membuat kode program seperti copy, paste, cut, searching dan replace text. Sketches yang sudah dibuat akan diperiksa dan menampilkan pesan error saat proses exporting. Pesan error juga memberikan informasi letak dari kesalahan pada sketches. Arduino IDE juga dilengkapi dengan pilihan jenis mikrokontroler yang digunakan nantinya. Fitur-fitur lainnya seperti verify, upload, new, open, save dan serial monitor memiliki fungsinya masing-masing [3].

A.M.Putra: Rancang Bangun Penyeimbangan Arus.....
1) Verify: Verify berfungsi melakukan pemeriksaan terhadap kode program yang dibuat agar tidak terdapat kesalahan baik secara struktur maupun perintah yang digunakan.

2) Upload:Upload memiliki fungsi untuk mengkompilasi kode program serta mengunduh kode program dari dalam modul mikrokontroler yang digunakan.

3) New:New berfungsi untuk menyediakan lembar kerja baru untuk membuat sketches.

4) Open: Fungsi dari fitur ini untuk membuka file kode program yang sudah pernah dibuat sebelumnya dan tersimpan dengan format ino.

5) Save: Save digunakan untuk menyimpan kode program atau sketches yang sudah dibuat.

6) Serial monitor: Serial monitor adalah fitur yang digunakan untuk monitoring kode program apakah sudah berfungsi sesuai dengan yang direncanakan.

\section{Sensor ArusSCT013-030}

Splilt-core Current Transformer adalah sensor arus yang menggunakan konsep kinerja dari trafo arus. Transformator arus dirancang untuk menghasilkan nilai arus sekunder yang lebih kecil dibandingkan sisi primernya. Trafo arus mengubah nilai arus pada suatu saluran transmisi ke nilai yang lebih kecil sehingga lebih aman untuk dilakukan pengukuran. Gambar 3akan menjelaskan cara kerja dari trafo arus.

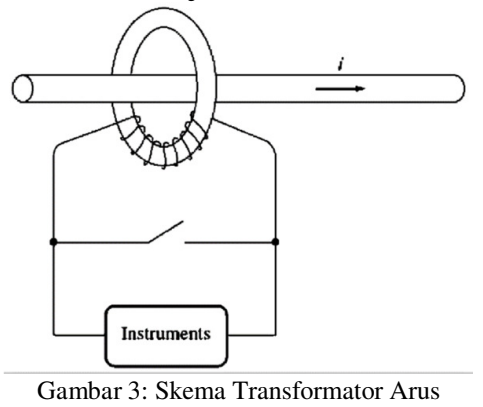

Trafo arus terdiri dari lilitan sekunder yang terdapat pada cicin ferromagnetic, dengan lilitan primer yang melewati bagian tengah dari cicin. Cicin ferromagnetic menahan sedikit fluks dari lilitan primer. Fluks ini menginduksi tegangan dan arus ke dalam lilitan sekunder. Rasio trafo arus antara lilitan primer dan sekunder mempengaruhi arus yang dihasilkan. Rasio transfomator arus biasanya berkisar antara 600:5, 800:5 atau 1000:5 ampere dengan rasio standar pada lilitan sekunder sebesar 5 ampere [4]. Sensor arus yang digunakan adalah sensor arus SCT013-030 dengan batas maksimum arus yang dapat diukur sebesar 30 ampere. Transformator arus ini menggunakan magnet permanen sebagai cincin ferromagnetic [5].

\section{E. Relay}

Pada elektronika, relay merupakan komponen yang paling sering digunakan untuk memutusatau menghubungkan suatu rangkaian secara terkontrol. Relay adalah saklar elektronik yang bekerja dengan memanfaatkan medan magnet.

p-ISSN:1693 - 2951; e-ISSN: 2503-2372 
Komponen ini terdiri dari lilitan dan lempengan yang berfungsi sebagai saklar. Saat lilitan dialiri arus listrik maka akan timbul medan magnet dan menarik lempengan. Relay yang digunakan adalah SPDT Songle Relay 12 volt. Adapun berbagai jenis relay berdasarkan kutubnya [6]:

1. COMMON yaitu kutub acuan.

2. NC (Normally Close) adalah kutub yang posisi awalnya terhubung dengan COMMON.

3. NO (Normally Open) adalah kutub dengan posisi awal terbuka dan akan terhubung dengan COMMON jika kumparan relay diberi arus listrik.

Berdasakan jumlah kutub pada relay, maka relay dibedakan menjadi empat jenis:
1. SPST = Single Pole Single Throw
2. SPDT = Single Pole Double Throw
3. DPST $=$ Double Pole Single Throw
4. DPDT = Double Pole Double Throw

Pole adalah jumlah COMMON, sedangkan Throw adalah jumlah terminal output (NO dan NC).

\section{F. $\quad$ LCD (Liquid Crystal Display)}

Penampil(display) elektronik adalah salah satu komponen elektronika yang berfungsi untuk menampilkan angka, huruf atau simbol-simbol lainnya. LCD (Liquid Crystal Display) adalah salah satu display elektronika yang umum digunakan. LCD dibuat dengan CMOS logic yang bekerja dengan tidak menghasilkan cahaya melainkan memantulkan cahaya yang ada di sekitarnya terhadap front-lit atau mentransmisikan cahaya dari back-lit. Jumlah karakter yang dapat ditampilkan oleh sebuah LCD tergantung dari spesifikasi yang dimiliki [7].

Terdapat beberapa pin yang penting untuk memberi perintah pada LCD, yakni:

1. Pin data adalah jalur data karakter yang ingin ditampikan dalam LCD, pin ini dapat dihubungkan dengan rangkaian lain seperti mikrokontroler dengan lebar data 8 bit.

2. Pin RS (register select) adalah pin yang berfungsi sebagai indikator untuk menentukan perintah yang masuk merupakan sebuah perintah atau data. Apabila logika nol (low) ini mengindikasikan bahwa yang masuk adalah perintah, sedangkan apabila logika satu (high) menandakan bahwa yang masuk adalah data.

3. Pin $\mathrm{R} / \mathrm{W}$ (read write) adalah pin yang berfungsi untuk membedakan perintah yang diberikan pada LCD untuk membaca data atau menulis data.

4. Pin E (enable) adalah pin yang berfungsi untuk memegang data yang masuk maupun keluar.

5. Pin VLCD adalah pin yang berfungsi untuk mengatur kecerahan dari tampilan LCD, pin ini biasanya dihubungkan dengan trimpot $10 \mathrm{k} \Omega$ dan tegangan $5 \mathrm{~V}$ digunakan sebagai sumber LCD.

\section{G. Transformator}

Transformator adalah peralatan listrik yang mampu mengubah energi listrik pada suatu nominal ke energi listrik dengan nominal lain menggunakan prinsip medan magnet.
Transformator sering disingkat dengan istilah trafo. Trafo terdiri dari dua buah lilitan kawat berisolasi pada suatu inti besi. Lilitan pada sisi primer akan terhubung dengan sumber selanjutnya disebut dengan lilitan input dan lilitan sekunder berfungsi sebagai lilitan output. Saat lilitan primer diberi tegangan maka timbul fluks, hal ini sesuai dengan hukum Faraday. Fluks yang berubah akan menginduksi tegangan pada lilitan sekunder dari transformator. Akibat dari induksi akan timbul beda potensial pada sisi sekunder, transfomator memiliki rasio perbandingan jumlah lilitan primer dan lilitan sekunder.

Apabila jumlah lilitan primer lebih banyak dibandingkan dengan lilitan sekunder maka trafo tersebut dikatakan sebagai trafo stepdown dan begitu juga sebaliknya, jika lilitan sekunder lebih banyak dibandingkan dengan lilitan primer maka trafo tersebut merupakan trafo step up[4]. Pada prototypemenggunakan transformator arus dengan keluaran 5 ampere, sisi primer dihubungkan menuju tegangan jala-jala 220 volt dan sisi sekunder akan menghasilkan output sebesar 6 volt, 9 volt dan 12 volt sesuai dengan spesifikasi yang dimiliki.

\section{METODE PENELITIAN}

Penelitian ini dilakukan di Laboratorium Dasar Teknik Elektro Fakultas Teknik Universitas Udayana mulai dari bulan Januari 2016 sampai dengan bulan Juni 2016. Adapun alur langkah penelitian dapat dilihat pada gambar 4 .

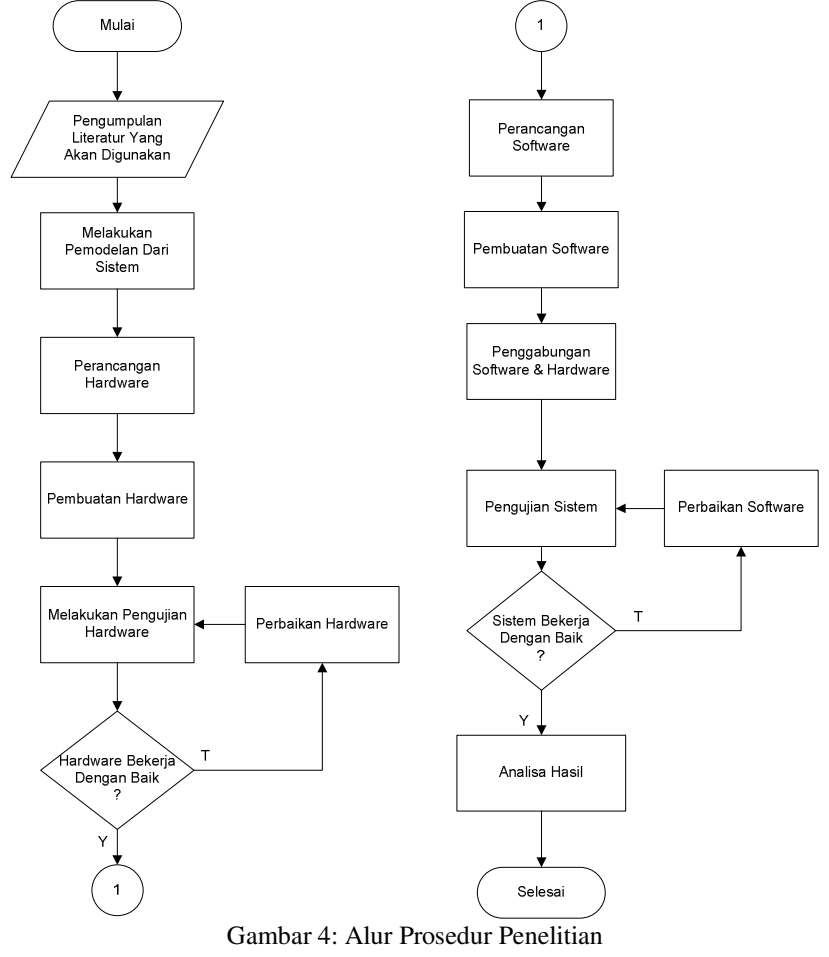

Langkah dari rancang bangun penyeimbangan arus beban pada sistem 3 fasa menggunakan mikrokontroler ATMega 2560 adalah sebagai berikut. 
1. Mengumpulkan literatur yang digunakan kemudian melakukan pemodelan dari sistem.

2. Dari pemodelan dilanjutkan dengan perancangan dan pembuatanhardwaredengan pengujian dan perbaikan hingga hardware bekerja dengan baik.

3. Selanjutnya dilakukan perancangan dan pembuatan software berupa program dan dilakukan penggabungan hardware dan software dengan pengujian hingga sistem bekerja dengan baik.

4. Apabila seluruh sistem dapat bekerja dengan baik dilakukan analisa untuk mendapatkan hasil, selesai.

A. Perancangna Perangkat Keras

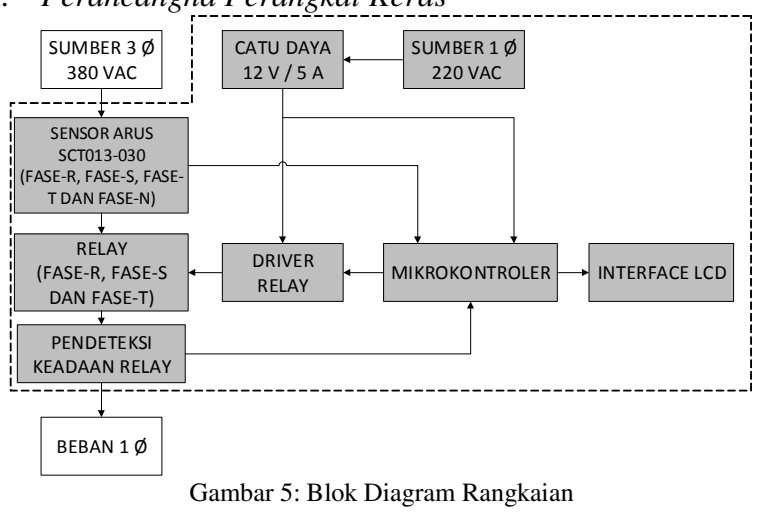

Perancangan perangkat keras dalam pembuatan rancang bangun penyeimbangan arus beban pada sistem 3 fasa menggunakan mikrokontroler ATMEGA 2560 sesuai dengan gambar 5adalah sebagai berikut:

1. Perancangan rangkaian catu daya.

2. Perancangan rangkaian driver relay.

3. Perancangan rangkaian sensor arus.

4. Perancangan rangkaian LCD.

5. Perancangan rangkaian mikrokontroler.

B. Perancangan Perangkat Lunak

Saat melakukan perancangan perangkat lunak diperlukan komputer yang sudah terpasang software arduino IDE (Integrated Development Enviroment) untuk membuat listing program sebagai perintah yang akan diterapkan pada mikrokontroler ATMega 2560.

\section{HASIL DAN PEMBAHASAN}

Hasil dan pembahasan untuk rancang bangun penyeimbang arus beban pada sistem 3 fasa menggunakan mikrokontroler ATMega 2560 adalah sebagai berikut.

\section{A. Realisasi Hasil Perancangan}

Realisasi rancang bangun penyeimbang arus beban pada sistem 3 fasa menggunakan mikrokontroler ATMega 2560 dapat dilihat pada gambar 6 .

A.M.Putra: Rancang Bangun Penyeimbangan Arus.....

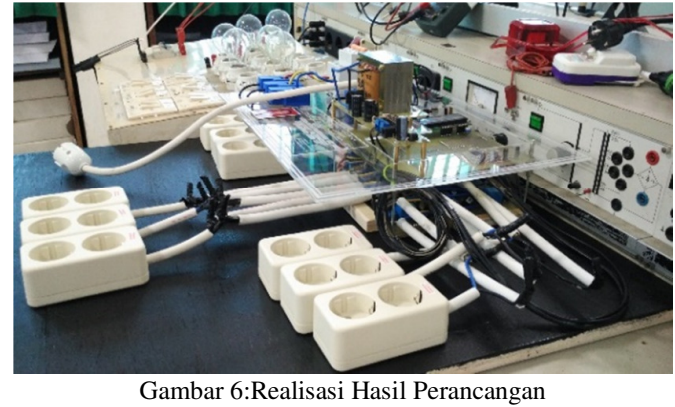

B. Pengujian Catu Daya

Pengujian rangkaian catu daya pada rancang bangun penyeimbang arus beban pada sistem 3 fasa menggunakan mikrokontroler ATMega 2560 dimaksudkan untuk mengetahui besarnya tegangan output yang dihasilkan dan mengetahui besarnya drop tegangan dalam keadaan berbeban.

TABEL 1: PENGUJIAN TEGANGAN

\begin{tabular}{|c|l|l|c|}
\hline No & Daerah Ukur & \multicolumn{1}{|c|}{ Kondisi } & Hasil Ukur (volt) \\
\hline \multirow{2}{*}{1} & \multirow{2}{*}{ IC LM 7809 } & Tanpa Beban & 8,94 \\
\cline { 3 - 4 } & & $\begin{array}{l}\text { Berbeban dengan } \\
\text { Arus 186,1 mA }\end{array}$ & 8,82 \\
\hline \multirow{2}{*}{2} & \multirow{2}{*}{ Diode Bridge } & $\begin{array}{l}\text { Tanpa Beban } \\
\text { Aerbeban dengan }\end{array}$ & 14,45 \\
\cline { 3 - 4 } & & Arus 293,3 mA & 13,17 \\
\hline
\end{tabular}

Dari hasil pengujian terhadap rangkaian catu daya memperoleh hasil seperti pada tabel 1 dimana terdapat drop tegangan yang diakibatkan dari pemasangan beban berupa rangkaian mikrokontroler dan driver relay. Besarnya penyimpangan hasil pengujian terhadap perancangan awal dapat dilihat pada tabel 2. Hasil penyimpangan tegangan keluaran pada rangkaian catu daya masih berada diantara batas tegangan kerja dari rangkaian pada prototype sehingga tegangan keluaran dari rangkaian catu daya dapat digunakan.

TABEL 2: PERSENTASE PENYIMPANGAN

\begin{tabular}{|c|c|c|c|}
\hline No & Daerah Ukur & Kondisi & Penyimpangan \\
\hline \multirow[b]{2}{*}{1} & \multirow[b]{2}{*}{ IC LM 7809} & Tanpa Beban & $0,67 \%$ \\
\hline & & $\begin{array}{l}\text { Berbeban dengan } \\
\text { Arus } 186,1 \mathrm{~mA}\end{array}$ & $2 \%$ \\
\hline \multirow[b]{2}{*}{2} & \multirow[b]{2}{*}{ Diode Bridge } & Tanpa Beban & $20,41 \%$ \\
\hline & & $\begin{array}{l}\text { Berbeban dengan } \\
\text { Arus } 293,3 \mathrm{~mA}\end{array}$ & $9,75 \%$ \\
\hline
\end{tabular}

C. Pengujian LCD (Liquid Crystal Display)

Hasil pengujian untuk rangkaian LCD (Liquid Crystal Display) dapat dilihat pada gambar 7, dimana LCD menampilkan karate bertuliskan 'arusR', 'arusS', 'arusT' dan

p-ISSN:1693 - 2951; e-ISSN: 2503-2372 
“arusN'. LCD yang digunakan memiliki spesifikasi penulisan dimensi $16 \times 2$ karakter.

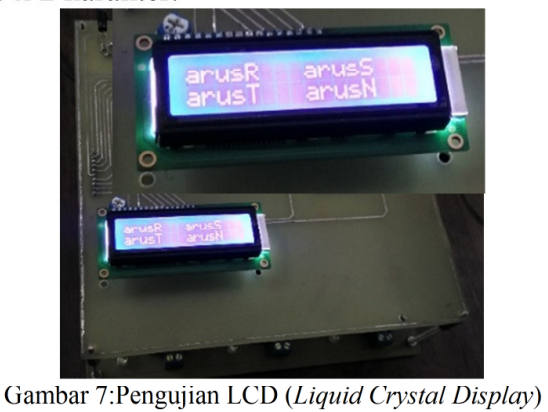

\section{Pengujian DriverRelay,}

Pengujian rangkaian driver relay dilakukan dengan memberikan perintah aktif untuk relay yang terhubung ke fasa $\mathrm{R}$, fasa $\mathrm{S}$, fasa $\mathrm{T}$ dan fasa $\mathrm{N}$ masing-masing sebanyak 3 buah. Pin mikrokontroler yang difungsikan sebagai output dihubungkan dengan driver relay. Tampilan hasil pengujian perintah aktif pada relay dapat dilihat pada gambar 8 .

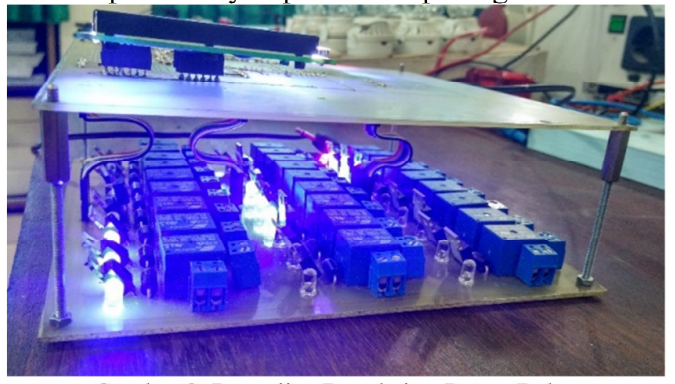

Gambar 8: Pengujian Rangkaian Driver Relay

\section{E. Pengujian Sensor Arus}

Pengujian sensor arus dilakukan dengan mengalungkan SCT013-030 pada kabel yang terhubung dengan beban 1 fasa. seperti yang terlihat pada gambar 9 dimana hasil pengukuran arus RMS menghasilkan nilai 0,55 ampere.

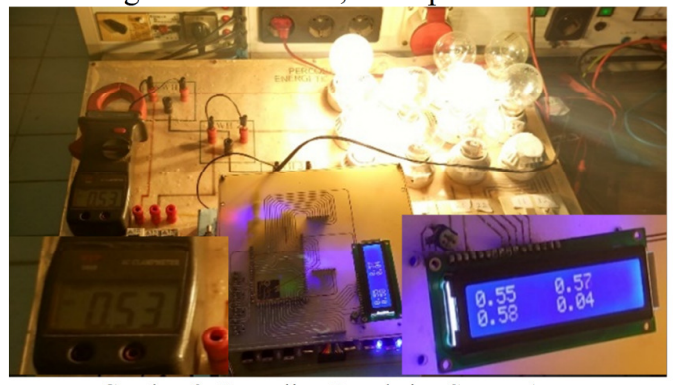

Gambar 9: Pengujian Rangkaian Sensor Arus

\section{F. Pengujian Mikrokontroler}

Pengujian rangkaian mikrokontroler dilakukan dengan memberikan perintah untuk menampilkan karakter yang bertuliskan 'Agus Mardiana Putra 1204405020' pada serial monitor. Hasil pengujian dapat dilihat pada gambar 10 dengan tampilan mengulang perintah secara terus menurus.

\begin{tabular}{|c|c|c|c|c|c|}
\hline (6) & & - & $\square$ & & $x$ \\
\hline I & & \multicolumn{4}{|c|}{ Send } \\
\hline 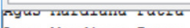 & & \multirow{2}{*}{\multicolumn{4}{|c|}{1204405020}} \\
\hline Agus Mardiana Putra & & & & & \\
\hline Aqus Mardiana Putra & & \multirow{2}{*}{\multicolumn{4}{|c|}{$\begin{array}{l}1204405020 \\
1204405020\end{array}$}} \\
\hline Agus Mardiana Putra & & & & & \\
\hline Agus Mardiana Putra & & \multicolumn{4}{|c|}{1204405020} \\
\hline Agus Mardiana Putra & & \multicolumn{4}{|c|}{1204405020} \\
\hline Agus Mardiana Putra & & \multicolumn{4}{|c|}{1204405020} \\
\hline Agus Mardiana Putra & & \multicolumn{4}{|c|}{1204405020} \\
\hline Agus Mardiana Putra & & \multicolumn{4}{|c|}{1204405020} \\
\hline Agus Mardiana Putra & & \multicolumn{4}{|c|}{1204405020} \\
\hline Agus Mardiana Putra & & \multicolumn{4}{|c|}{1204405020} \\
\hline Agus Mardiana Putra & & \multicolumn{4}{|c|}{1204405020} \\
\hline Agus Mardiana Putra & & \multicolumn{4}{|c|}{1204405020} \\
\hline Agus Mardiana Putra & & \multicolumn{4}{|c|}{1204405020} \\
\hline Agus Mardiana Putra & & \multicolumn{4}{|c|}{1204405020} \\
\hline Agus Mard & & \multirow{2}{*}{\multicolumn{4}{|c|}{,}} \\
\hline$<$ & & & & & \\
\hline$\square$ Autoscroll & No line ending & & 9600 & baud & \\
\hline
\end{tabular}

\section{G. Pengujian Keseluruhan Sistem}

Pengujian keseluruhan sistem dilakukan dengan enam buah siluasi dan kondisi yang berbeda-beda. Pengujian yang pertama mengkondisikan fasa $\mathrm{R}$ memiliki arus beban terbesar. Pengujian dengan kondisi ini dilakukan sebanyak dua kali, pertama arus beban terkecil berada di fasa $\mathrm{S}$ dan kedua arus beban terkecil pada fasa T. Pada gambar 11 merupakan kondisi arus beban pada sistem 3 fasa dengan arus beban terkecil berada di fasa $\mathrm{S}$.

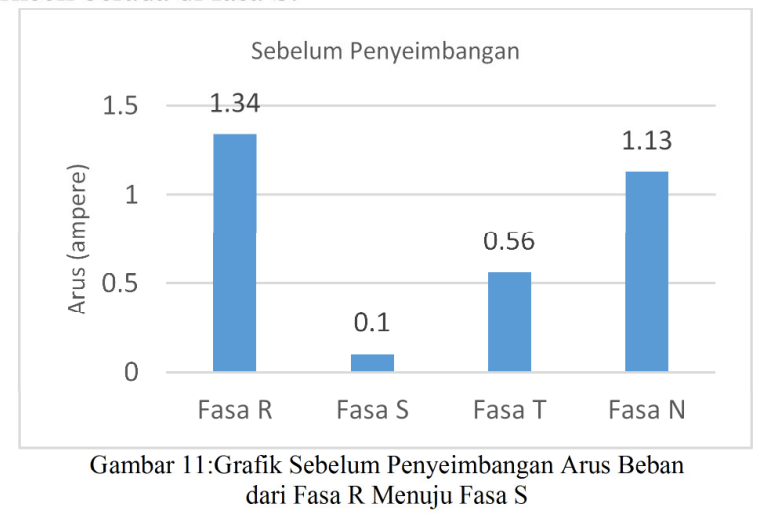

Setalah prototype melakukan penyeimbangan arus beban karena arus netral melebihi 1 ampere maka hasilnya dapat dilihat pada gambar 12 dimana arus netral turun menjadi 0,82 ampere.

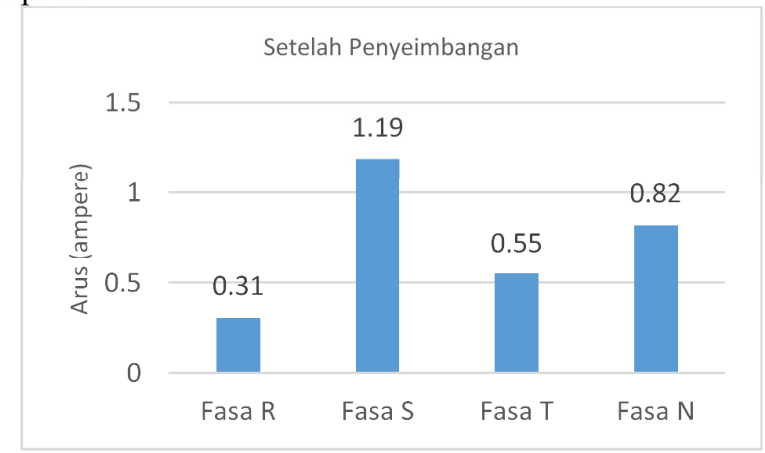

Gambar 12:Grafik Setelah Penyeimbangan Arus Beban dari Fasa R Menuju Fasa S 
Pada gambar 13 merupakan kondisi arus beban pada sistem 3 fasa dengan arus beban terkecil berada di fasa $T$.

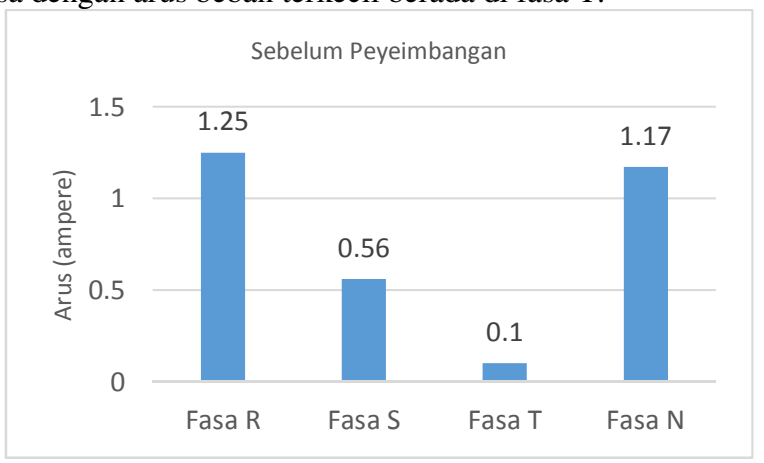

Gambar 13:Grafik Sebelum Penyeimbangan Arus Beban dari Fasa R Menuju Fasa T

Setalah prototype melakukan penyeimbangan arus beban karena arus netral melebihi 1 ampere maka hasilnya dapat dilihat pada gambar 14 dimana arus netral turun menjadi 0,93 ampere.

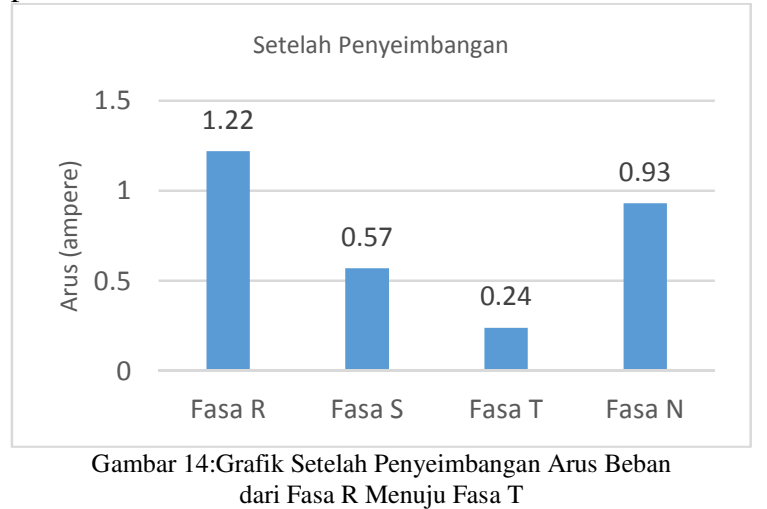

Pengujian yang kedua mengkondisikan fasa S memiliki arus beban terbesar. Pengujian dengan kondisi ini dilakukan sebanyak dua kali, pertama arus beban terkecil berada di fasa $\mathrm{R}$ dan kedua arus beban terkecil pada fasa T. Pada gambar 15 merupakan kondisi arus beban pada sistem 3 fasa dengan arus beban terkecil berada di fasa $\mathrm{R}$.

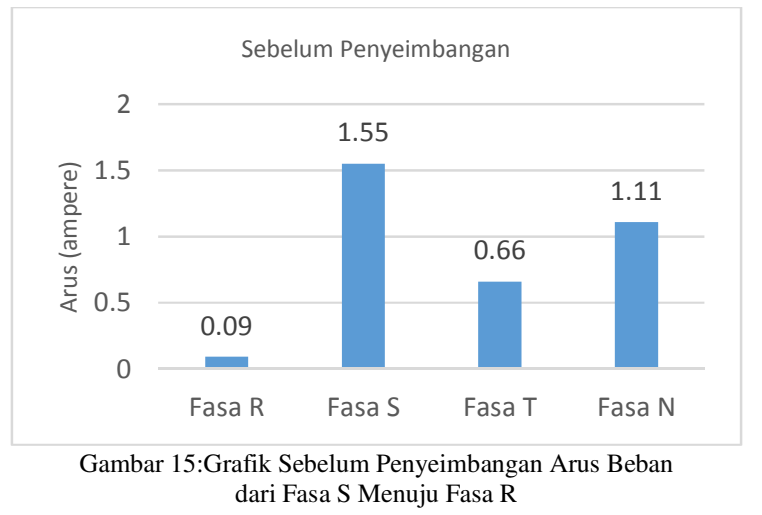

Setalah prototype melakukan penyeimbangan arus beban karena arus netral melebihi 1 ampere maka hasilnya dapat A.M.Putra: Rancang Bangun Penyeimbangan Arus..... dilihat pada gambar 16 dimana arus netral turun menjadi 0,84 ampere.

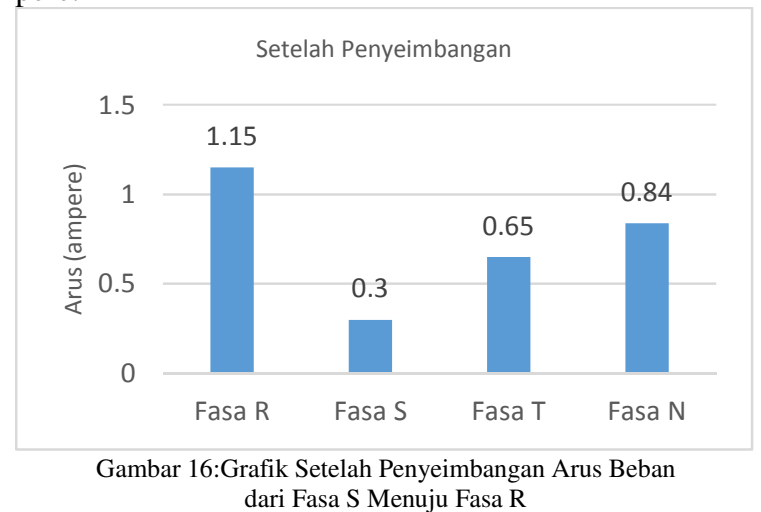

Pada gambar 17 merupakan kondisi arus beban pada sistem 3 fasa dengan arus beban terkecil berada di fasa $T$.

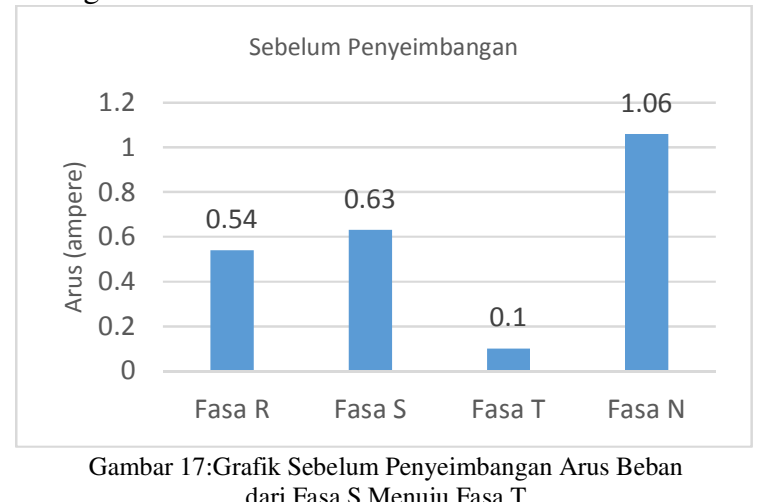

Setalah prototype melakukan penyeimbangan arus beban karena arus netral melebihi 1 ampere maka hasilnya dapat dilihat pada gambar 18 dimana arus netral turun menjadi 0,64 ampere.

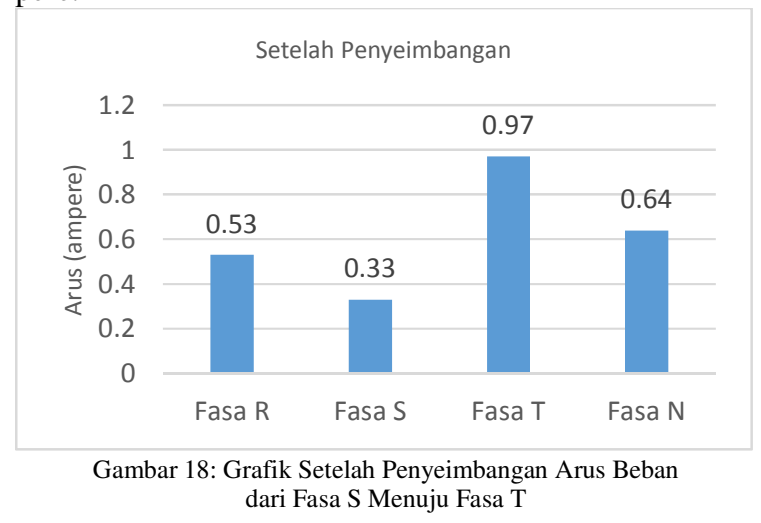

Pengujian yang kedua mengkondisikan fasa $\mathrm{T}$ memiliki arus beban terbesar. Pengujian dengan kondisi ini dilakukan sebanyak dua kali, pertama arus beban terkecil berada di fasa $\mathrm{R}$ dan kedua arus beban terkecil pada fasa S. Pada gambar 19 merupakan kondisi arus beban pada sistem 3 fasa dengan arus beban terkecil berada di fasa $\mathrm{R}$.

p-ISSN:1693 - 2951; e-ISSN: 2503-2372 


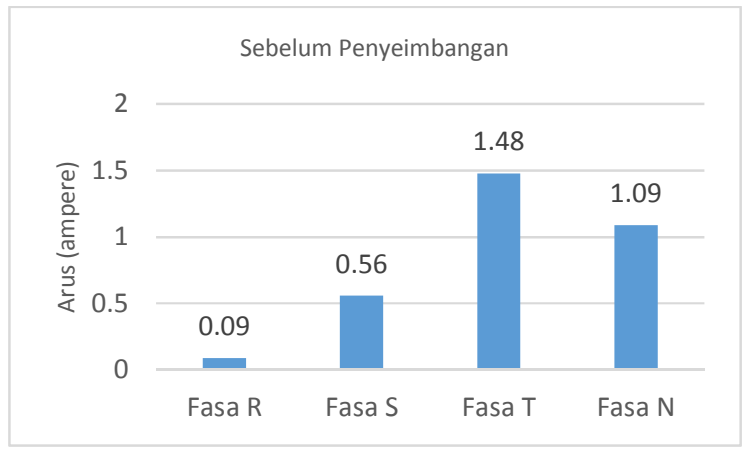

Gambar 19:Grafik Sebelum Penyeimbangan Arus Beban dari Fasa T Menuju Fasa R

Setalah prototype melakukan penyeimbangan arus beban karena arus netral melebihi 1 ampere maka hasilnya dapat dilihat pada gambar 20 dimana arus netral turun menjadi 0,83 ampere.

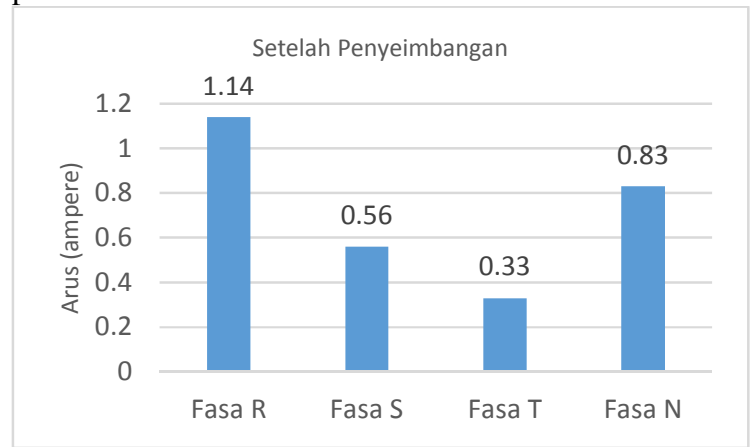

Gambar 20: Grafik Setelah Penyeimbangan Arus Beban dari Fasa T Menuju Fasa R

Pada gambar 21 merupakan kondisi arus beban pada sistem 3 fasa dengan arus beban terkecil berada di fasa $S$.

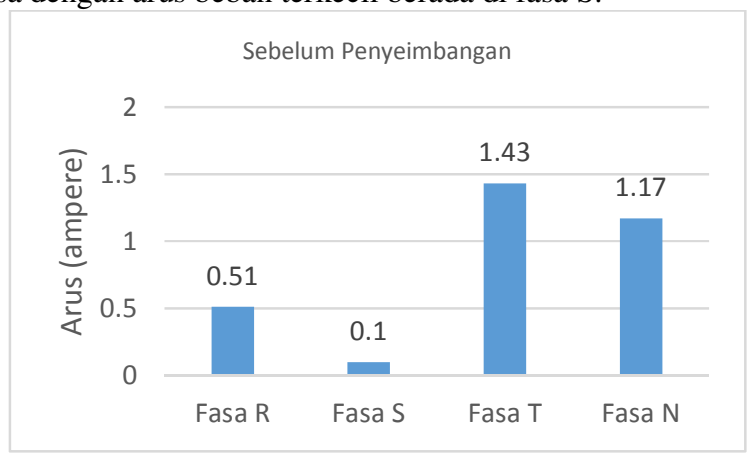

Gambar 21:Grafik Sebelum Penyeimbangan Arus Beban dari Fasa T Menuju Fasa S

Setalah prototype melakukan penyeimbangan arus beban karena arus netral melebihi 1 ampere maka hasilnya dapat dilihat pada gambar 22 dimana arus netral turun menjadi 0,85 ampere.

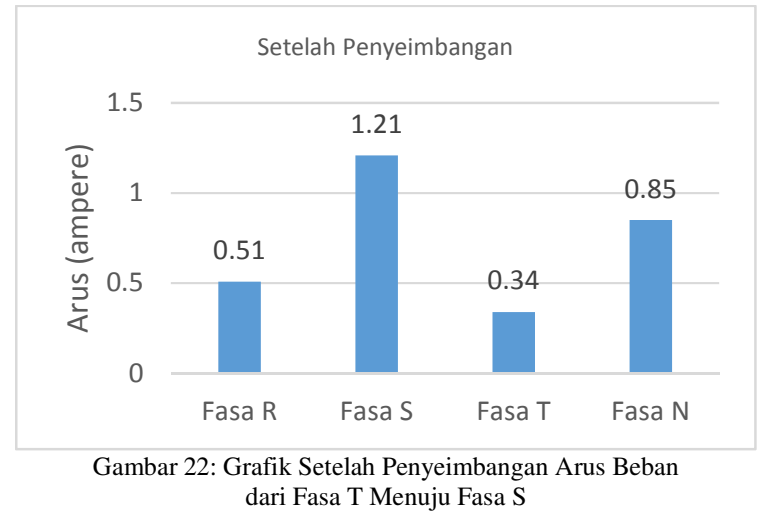

Berdasarkan hasil pengujian keseluruhan sistem pada rancang bangun penyeimbangan arus beban pada sistem 3 fasa menggunkan mikrokontroler ATMega 2560 dengan 6 kondisi, alat mampu melakukan penyeimbangan arus beban sehingga arus netral berkurang dan pengujian dapat dikatakan berhasil.

\section{SIMPULAN}

Berdasarkan hasil pengujian yang dilakukan pada rancang bangun penyeimbangan arus beban pada sistem 3 fasa menggunakan mikrokontroler ATMega 2560 dapat disimpulkan.

1) Rancang bangun penyeimbangan arus beban pada sistem 3 fasa menggunakan mikrokontroler ATMega 2560 telah berhasil dilakukan dengan menggunakan sensor arus SCT013-030 sebagai nilai input dan mikrokontroler ATMega 2560 sebagai pengolah data untuk menghasilkan perintah output.

2) Hasil pengujian menunjukkan penyeimbangan arus beban pada sistem 3 fasa dilakukan dengan mendeteksi besarnya arus netral, saat arus netral melebihi 1 ampere $+10 \%$ maka prototype akan mendeteksi fasa yang memiliki arus beban terbesar. Selanjutnya prototype mendeteksi urutan nomor beban yang tersambung ke fasa tersebut, pemindahan saluran beban dilakukan dari fasa yang memiliki nilai arus beban terbesar menuju fasa dengan nilai arus beban terkecil dimulai dari urutan nomor beban terkecil dimana penomoran saluran beban sudah ditentukan sebelumnya.

3) Pengujian dengan seluruh situasi dan kondisi yang digunakan memberikan hasilprototype mampu melakukan penyeimbangan arus beban mengakibatkan nilai arus netral berkurang sehingga rugi daya akibat ketidakseimbangan arus beban pada sistem 3 fasa menjadi berkurang.

4) Penyeimbangan arus beban olehprototype mampu mengurangi waktu penanganan situasi ketidakseimbangan arus beban pada sistem 3 fasa pada gardu distribusi sehingga rugi daya bagi PT.PLN (Persero) menjadi berkurang berdasarkan lama waktu penanganan di lapangan.

\section{REFERENSI}

[1] Anonim. (2010) Wordpress page. [online]. Available: http://arrester.wordpress.com/20100/10/16/gardu-tiang-trafo-gtt/ 
[2] Sakti U. P., "Evaluasi Pemerataan Beban untuk Menekan Losses Jaringan Tegangan Rendah di Gardu E311P dan Gardu PM 213", Jakarta: PT. PLN (Persero). 2008.

[3] (2016) The Arduino website. [online]. Available: https://www.arduino.cc/

[4] S. J. Chapman, Electric Machinery Fundamentals, $4^{\text {th }}$, Australia: BAE SYSTEM, 2005.

[5] "SCT013-030V data sheet", Split-core current transformer, Beijing YaoHuadechang Electronic Co., Ltd, China.

[6] R. Boylestad and L. Nashelsky, Electronic Device and Circuit Theory, $7^{\text {th }}$, United States: Pretince Hall, 2007.

[7] (2016) The Revolution Education website. [online]. Available: www.rev-ed.co.uk 
\{sengaja di kosongkan\} 